Оригинальная статья/Original article

УДК 331.104.2

DOI: http://doi.org/10.20914/2310-1202-2017-1-416-421

Формирование и значение корпоративной культуры в системе управления

\begin{tabular}{lll}
\hline \hline Антон В. Богомолов & 1 & uopioe@yandex.ru \\
Екатерина А. Белимова & 2 & e.a.belimova@gmail.com \\
Елжан Б. Кушекбаев & 3 & yelzhan@gmail.com \\
\hline
\end{tabular}

$\mathbf{1}$ Воронежский государственный промышленно-гуманитарный колледж, пр-т Революции, 20, г. Воронеж, 394036, Россия ${ }^{2}$ Воронежский государственный университет инженерных технологий, пр-т Революции, 19, г. Воронеж, 394036, Россия ${ }^{3}$ Алматинский университет управления, ул. Розыбакиева, 227, Алматы, 050060, Казахстан

Реферат. Рассмотрена корпоративная культура как инструмент управления в экономической модели деятельности, лежащей в основе организации управления всеми факторами производства (трудовыми ресурсами, материалами, капиталом и информацией). Успешнее развиваются компании, имеющие хорошо развитую корпоративную культуру. Слабая корпоративная культура может стать источником глубокого кризиса предпринимательской структуры. Выделено, что совокупность факторов, влияющих на развитие предпринимательских структур, необходимо дополнить фактором эффективной корпоративной культуры. Реформы, направленные на изменения в отношениях собственности, требуют создания адекватного организационно-экономического механизма управления корпоративными предприятиями с учетом современных тенденций концентрации и специализации агропромышленного производства. Представлена корпоративная культура, включающая стратегическую цель фирмы; эталоны поведения персонала; структурные характеристики персонала, характер, содержание, условия труда и методы его организации; систему стимулов; систему обучения персонала. Выделены виды корпоративной культуры и их особенности, а именно культуры власти, культуры ролей, культуры задач и культуры индивидуальностей. Уникальная сущность корпоративной культуры, сложность ее оценки создают определенные проблемы при управлении корпоративной культурой. Корпоративная культура дает возможность грамотно и эффективно управлять организацией. Сильная и монолитная корпоративная культура является необходимым атрибутом успешной компании, поскольку она объединяет сотрудников, которые отождествляют себя со своей организацией и стремятся к достижению единой цели совместными усилиями. В такой компании ключевые корпоративные ценности разделяются всеми членами организации, доминирующая культура сильно влияет на поведение сотрудников, исчезает необходимость в высокой структуризации и формализации деятельности компании, снижается текучесть кадров.

Ключевые слова: корпоративная культура, управление компании, факторы, инструменты, структуры, типы

\title{
Formation and importance of corporate culture in the system of
} management

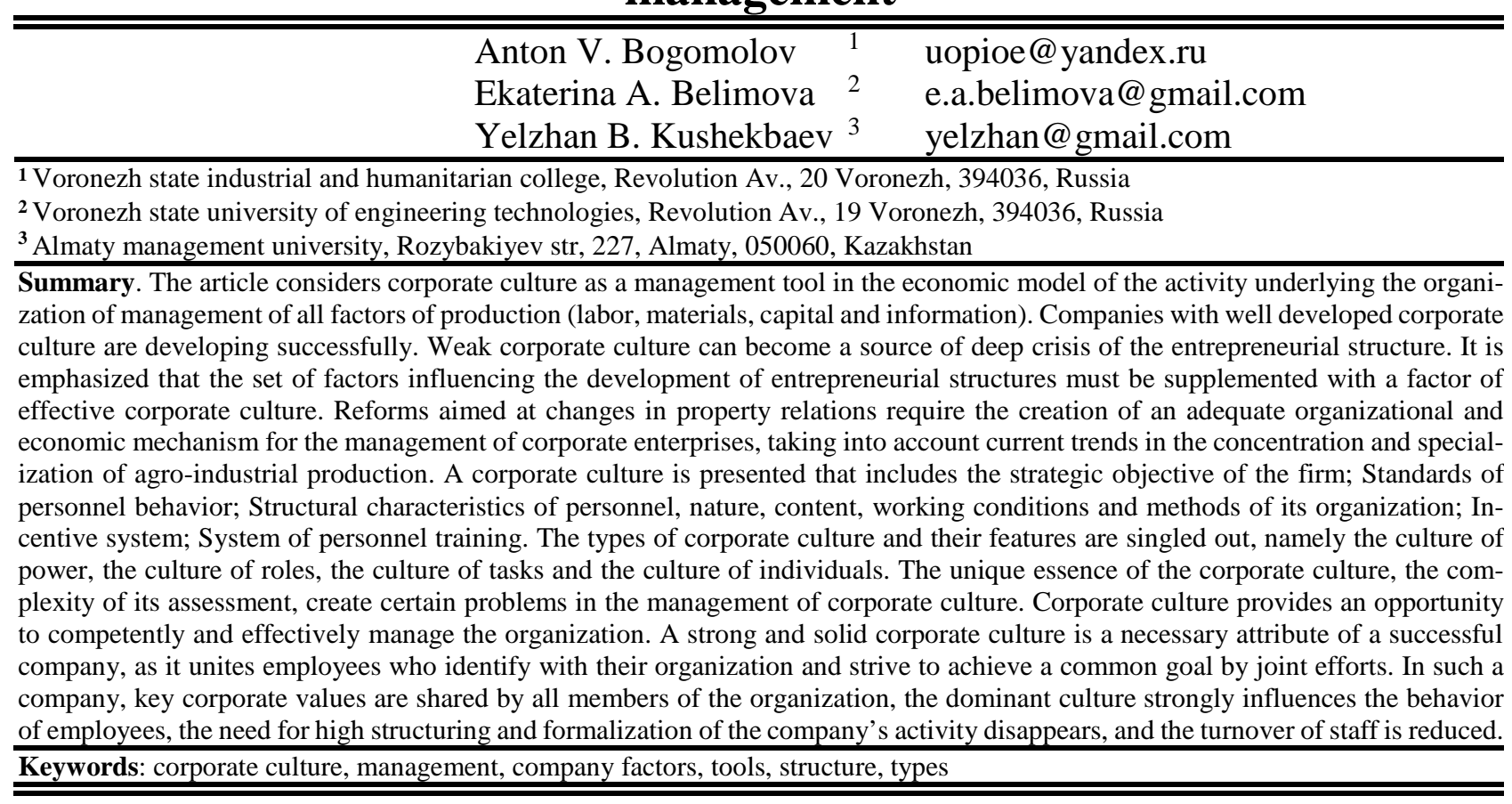

Для цитирования

Богомолов А.В., Белимова Е.А., Кушекбаев Е.Б. Формирование и значение корпоративной культуры в системе управления // Вестник ВГУИТ. 2017. Т. 79. № 1. С. 416-421. doi:10.20914/2310-12022017-1-416-421
For citation

Bogomolov A.V., Belimova E.A., Kushekbaev Ye.B. Formation and importance of corporate culture in the system of management. Vestnik VGUIT [Proceedings of VSUET]. 2017. Vol. 79. no. 1. pp. 416-421. (in Russian). doi:10.20914/2310-1202-2017-1-416-421 


\section{Введение}

Усиление конкуренции, постоянные изменения во внешней среде, усложнения в производственной и коммерческой деятельности предприятий, повышение значения фактора времени, расширение масштабов деятельности предприятия и увеличение объёмов и скорости получения информации и новых знаний повышают значимость внутренних источников экономического роста, способных обеспечить эффективность предпринимательской деятельности. Важнейшим ресурсом, способным создать адаптивную, эффективную производственную систему, является корпоративная культура, поскольку именно она определяет каким образом достигаются результаты деятельности предприятия, обусловливая изменение соотношения между объёмом производства и измеряемыми затратами.

\section{Основная часть}

Корпоративная культура является важнейшим инструментом управления, лежащим в основе построения любой экономической модели деятельности. Как система элементов, корпоративная культура лежит в основе организации управления всеми факторами производства (трудовыми ресурсами, материалами, капиталом и информацией). Быстрее всех развиваются компании, имеющие хорошо развитую корпоративную культуру. Поэтому совокупность факторов, влияющих на развитие предпринимательских структур, необходимо дополнить фактором эффективной корпоративной культуры [1].

Слабая корпоративная культура может стать источником глубокого кризиса предпринимательской структуры. Это может произойти в случае слияния/поглощения компаний, смены собственников или руководства, смены поколений персонала, расширения, изменения стратегии компании (преобразования бизнес-процессов). Одной из основных причин возникновения кризиса является отсутствие систематической и целенаправленной работы по развитию и адаптации корпоративной культуры к меняющимся условиям внешней и внутренней среды.

Уникальная сущность корпоративной культуры, сложность ее оценки создают определенные проблемы при управлении корпоративной культурой. Корпоративная культура дает возможность грамотно и эффективно управлять организацией, при этом является направлением, недостаточно изученным в Казахстане.

Проводимые в Казахстане реформы, направленные на изменения в отношениях собственности, требуют создания адекватного организационно-экономического механизма управления корпоративными предприятиями с учетом современных тенденций концентрации и специализации агропромышленного производства, что будет способствовать быстрому внедрению результатов научно-технического прогресса и в итоге создаст условия для повышения экономической эффективности деятельности предприятий, качества и конкурентоспособности продукции агропромышленного комплекса.

Значение управления в интегрированных предприятиях для долгосрочной перспективы развития резко возросло в последние десятилетия, что обусловлено ускорением изменений в окружающей среде, появлением новых запросов потребителей и изменением их позиций, а также рядом других факторов. Корпоративная культура не только отличает одну организацию от другой, но и предопределяет успех функционирования и выживания ее в перспективе. Она позволяет обеспечить высокую прибыльность организации посредством совершенствования управления, обеспечения лояльности сотрудников к руководству и принимаемым им решениям, воспитания отношения к организации как к своему дому, что приводит к максимизации эффективности производственного менеджмента и общим качественным улучшениям деятельности.

Корпоративная культура включает всю систему социально-трудовых отношений: социализированную стратегическую цель фирмы; эталоны поведения персонала; структурные характеристики персонала (образовательные, этнические, национальные, демографические); способы ведения хозяйства; характер, содержание, условия труда и методы его организации; систему стимулов; систему обучения персонала и др. Выделяют следующие виды корпоративной культуры [2].

Бюрократическая культура характеризуется регулированием всех сторон деятельности организации документами, четкими правилами, процедурами; оценкой персонала по формальным принципам и критериям. Источником власти, сконцентрированной в руках руководства, здесь является должность. Такая культура гарантирует людям стабильность, безопасность, избавляет от конфликтов.

Предпринимательская культура поддерживает действия, направленные вовне организации и на перспективу, новаторство и творческую активность персонала. Гарантирует удовлетворение потребностей работников в развитии и совершенствовании. Управление здесь основывается на вере в руководителя, его знаниях и опыте, а также привлечении персонала к творчеству. 
Партиципативная организационная культура ориентирует профессионалов на собственный профессиональный рост, овладение новыми знаниями, удовлетворение потребности в самораскрытии. Если в такой организации встает вопрос о сокращении персонала, то каждый должен оценить, с одной стороны, насколько организация в ее нынешнем состоянии способна помочь ему в профессиональном росте, с другой - чем он сам может быть полезен организации и коллегам. Главный механизм такого понимания - самоформирование целевых команд под проекты, что позволяет организации снизить бремя неэффективных затрат, переведя персонал на работу по проектам, имеющим финансирование. Кроме того, сотрудники получают возможность эффективно использовать собственное время.

Корпоративная культура играет очень важную роль в жизни организации, поэтому она должна быть предметом самого пристального внимания руководства. Менеджмент призван не только соответствовать корпоративной культуре, так как сильно зависит от нее, но и, в свою очередь, оказывать влияние на ее формирование и развитие.

Корпоративная культура формируется под воздействием стихийных и направленных факторов. К первым относятся внешняя среда, в которой функционирует организация, включая общественные нормы, рыночную и экономическую ситуацию, место организации в обществе. Ко вторым относятся целенаправленные действия руководства и рядовых сотрудников по формированию корпоративной культуры.

На практике, руководители редко сталкиваются с возможностью формировать корпоративную культуру «с нуля». Это возможно, если организация только создана и начинает работать. Обычно построение корпоративной культуры связано с необходимостью изменить уже сформировавшуюся в организации культуру. Существует большое количество моделей формирования корпоративной культуры. Следует использовать следующее при построении новой культуры в существующей организации:

1. Измените или сформулируйте заново интеллектуальную концепцию организации [3]. Сотрудники и клиенты должны понимать, для чего работает ваша фирма, каковы ее ценности и подходы к работе;

2. Продемонстрируйте сотрудникам приверженность руководства к организационной культуре. Руководители должны стать трансляторами ценностей организации. Кроме этого, они должны формально и неформально поощрять принятие корпоративной культуры сотрудниками.

3. Создайте условия, благоприятные для развития и укрепления корпоративной культуры. Например, если вы декларируете, что частью корпоративной культуры является взаимовыручка, поощряйте сотрудников за совместное решение задач и не допускайте явной внутренней конкуренции.

4. Учитывайте особенности корпоративной культуры, отбирая и адаптируя новых сотрудников. Организациям, декларирующим клиентоориентированность, не стоит брать на работу конфликтных специалистов.

5. Поощряйте как соблюдение норм корпоративной культуры, так и конструктивные инновационные предложения. Культура организации должна развиваться и адаптироваться к особенностям среды. Формирование корпоративной культуры - бесконечный процесс. Если вы активно формируете культуру своей организации, то замечаете первые результаты спустя годы. Однако вряд ли вы когда-нибудь захотите остановиться и сказать, что культура компании больше не нуждается в развитии.

Корпоративная культура может быть оценена, проконтролирована, управляема.

Критерии ее анализа следующие: «толщина» - относительная величина, показывающая удельный вес определяющей организационной культуры в общем количестве признаваемых членами организации культур; разделяемость взглядов - показатель, характеризующий количество основных положений, норм, ценностных ориентации, традиций и т. д., абсолютно принимаемых всеми членами организации; «широта» - величина, характеризующая количественное отношение членов организации, для которых эта культура доминирующая, к общему числу членов организации.

К критерию анализа следует отнести: конфликт - ситуацию, в которой определяющей становится не одна организационная культура, а две (несколько); следует учитывать, что конфликт организационных культур может быть не только негативным, но и позитивным в зависимости от стратегии организации: для нормально функционирующей, то есть финансово устойчивой организации, имеющей необходимый рынок сбыта, конфликт организационных культур становится необходимым фактором развития, расширения.

Имеет значение критерий анализа: «сила» - степень проявления организационной культуры и ее влияния на поведение персонала (слабую организационную культуру можно 
распознать по таким признакам, как отсутствие ясных представлений о ценностях и общих убеждений относительно того, как достичь успеха в определенном деле; беспомощности, поиске спасения в постановке краткосрочных целей; отсутствии согласия между отдельными частями организации и др.).

Менеджеры призваны уметь анализировать практику корпоративной культуры, влиять на ее формирование и изменение в лучшую сторону. При ее анализе следует выделять три основных момента. Первый момент - это базовые предположения, которых придерживаются члены организации в поведении и действиях. Они нередко связаны с видением окружающей среды (группы, организации, общества и т. д.) и регулирующих ее переменных (природа, время, работа, характер отношений и т. д.).

Второй момент - это ценности (или ценностные ориентации), которых придерживается человек. Ценности ориентируют, какое поведение можно считать допустимым. В некоторых организациях считается, что «клиент всегда прав», поэтому нельзя обвинять клиента за неудачу в работе. Ценности помогают работнику понять, как он должен действовать в конкретной ситуации.

Третий момент - это «символика», посредством которой ценностные ориентации «передаются» членам организации. Некоторые организации имеют специальные документы, в которых детально описаны ценностные ориентации. Содержание и значение последних наиболее полно раскрывают «ходячие» истории, легенды и мифы. Они иногда оказывают большее влияние на людей, чем ценности, записанные в рекламном буклете компании.

При анализе организационной культуры могут быть выявлены стратегически важные критические ситуации, когда она не соответствует функциям структурных подразделений, функциональному или морфологическому содержанию организации, структуре управления, стадии развития, стратегии организации. Каждая критическая ситуация требует индивидуального подхода, сложного ряда взаимосвязанных выводов и решений [4].

Успех организации предполагает высокую степень совместимости стратегии и организационной культуры. Чтобы достичь этого, выделяют следующие подходы: игнорируют культуру, препятствующую эффективному выполнению выбранной стратегии; систему управления подстраивают под существующую организационную культуру; подход основан на признании барьеров, создаваемых культурой, для проведения желаемой стратегии и выработке альтернатив по «обходу» этих барьеров без серьезных изменений в самой стратегии; пытаются изменить культуру в соответствии с выбранной стратегией; стратегию подстраивают под существующую культуру.

Корпоративная культура закрепляется и поддерживается так называемой фирменной философией, отражающей нравственно-деловое кредо организации, фиксирующей ее ценности и цели деятельности в функционально-специализированных областях. Приобщение сотрудников к корпоративной культуре, воспитание в них готовности действовать в ее духе и демонстрировать соответствующие образцы организационного поведения считаются в современной науке и практике управления ключевым направлением работы менеджера. В корпоративной культуре проявляется и культура личности, в том числе культура мышления, речи, исполнения, законопослушность, соблюдение норм служебной этики.

Одна из важнейших задач казахстанского HR-менеджмента может быть сформулирована примерно следующим образом - определение и изучение национально-страновых особенностей корпоративной культуры Казахстана с дальнейшим выведением рекомендаций для наиболее типичных ситуаций.

Использование модели Г. Хофстеде для общей оценки корпоративной казахстанской культуры позволило определить следующие её особенности: авторитарный стиль управления и жёсткая централизация.

При этом иерархическая структура казахстанских предприятий может быть довольно «размазанной» с концентрацией большей части властных полномочий в руках так называемого серого кардинала - промежуточное положение между индивидуализмом или коллективизмом. В то время как предприятия южных и западных регионов страны ориентированы на коллективизм, для северных и восточных областей, напротив, более характерна направленность на индивидуализм. Большинство руководителей принимает решения на основе рационального мышления, доминируют такие ценности, как возможность признания, успеха, карьерного роста, материального благополучия, реализации амбиций.

Рассматривая традиционные ценности казахстанского предпринимательства в современном контексте, можно обнаружить их отражение в партнерской корпоративной культуре, основанной на принципах сотрудничества, справедливости и эффективности.

Компания, придерживающаяся партнерской корпоративной культуры, ориентируется 
на долгосрочные перспективы, а сотрудники представляют в ней основную ценность. Партнерская организация стремится раскрыть творческий потенциал каждого работника и создать все условия для появления трудового подъема. Восприятие справедливости как ценности в такой организации выражается в выполнении следующих базовых условий: хозяйственная деятельность в соответствии с законодательством, честные и открытые отношения; определенный уровень гарантии занятости; достойная оплата труда; внимательное и уважительное отношение к работникам со стороны руководства, выполнение данных им обещаний.

Понимание товарищества как ценности в партнерской культуре позволяет поддерживать здоровый организационный климат, способствует созданию позитивных межличностных отношений и командной работы как внутри отделов, так и между подразделениями компании.

Еще один элемент партнерской корпоративной культуры - демократический стиль управления (активный стиль лидерства, ориентированный на достижение заинтересованности работников в успешной деятельности организации) [5].

Согласно известной модели определения влияния национального на корпоративную культуру, стиль управления и система контроля в организации основываются на представлениях о природе человека в обществе (варианты: человек изначально «плохой», «нейтральный» или «хороший»). Ориентация на «плохое» в природе человека служит основой авторитарного стиля управления и жесткой системы контроля.

Главная особенность партнерской корпоративной культуры состоит в ее назначении (миссии), что также соответствует национальным традициям отечественного хозяйствования [6].

Менеджеры используют различные способы типологии корпоративной культуры. Например, ирландский эксперт по организационной психологии Чарльз Хэнди выделяет следующие типы корпоративной культуры:

\section{ЛИТЕРАТУРА}

1 Кибанов А. Я. Основы управления персоналом: учебник, Москва: ИНФРА-М, 2012.

2 Белимова Е. А., Алексеева В. А. Управление человеческими ресурсами: инновационный подход // Экономика. Инновации. Управление качеством.. 2013. № 3. С. 62 .

3 Bolton P., Brunnermeier M.K., Veldkamp L. Leadership, Coordination and Corporate Culture, 2014.

4 Нурланова Н. К. The problems of spatial modernization of the economy and new approaches to
1. Культура власти. Для нее характерна концентрация управленческих функций в руках небольшой группы людей или одного человека, авторитарный стиль руководства, жесткий контроль за исполнением решений, низкий уровень бюрократизации.

2. Культура ролей. Для этого типа характерны высокий уровень бюрократизации, делегирование обязанностей и прав в зависимости от занимаемой должности, но не личной компетенции, коллективное принятие решений, контроль в соответствии со сложными процедурами.

3. Культура задач. Этот тип характеризуется наличием небольших групп сотрудников, ответственных за решение определенного круга задач. Права и обязанности делегируются сотрудникам, способным выполнять те или иные действия. Культура задач принята в организациях, где большинство сотрудников имеют хорошие профессиональные качества и способны работать на результат.

4. Культура индивидуальностей. Этот тип формируется в организациях, большинство членов которых считают, что в одиночку работают лучше, чем в группе. Это ставит под вопрос существование таких предприятий. Однако фирма с культурой индивидуальностей может успешно существовать, если ее сотрудники заинтересованы в профессиональных знаниях и умениях друг друга.

\section{Заключение}

Сильная и монолитная корпоративная культура является необходимым атрибутом успешной компании, поскольку она объединяет сотрудников, которые отождествляют себя со своей организацией и стремятся к достижению единой цели совместными усилиями. В такой компании ключевые корпоративные ценности разделяются всеми членами организации, доминирующая культура сильно влияет на поведение сотрудников, исчезает необходимость в высокой структуризации и формализации деятельности компании, снижается текучесть кадров.

way out from crisis: Kazakhstan's experience // Journal of Distribution Science. 2013. C. 39-48.

5 Fiordelisi F., Ricci O. Corporate culture and CEO turnover // J. Corp. Finance. 2013.

6 Querubin S.Y., Jon K.W. Developing corporate culture in a training department: a qualitative case study of internal and outsourced staff // Global Conference on Business and Finance. 2014. № 1.

7 Varlamov N. V., Polyanin A. V. Scientific approaches for development of corporate management theory // Russian journal of agricultural and socio-economic sciences. 2017. T. 62. № 2. C. 4-11. 


\section{REFERENCES}

1 Kibanov A. Ya. Osnovy upravleniya personalom: uchebnik [Fundamentals of personnel management]. Moscow, INFRA-M, 2012. (in Russian).

2 Belimova E. A., Alekseeva V. A. Human resource management: an innovative approach. Ekonomika. Innovatsii. Upravlenie kachestvom. [Economy. Innovation. The management of quality.]. 2013. no. 3. pp. 62. (in Russian).

3 Bolton P., Brunnermeier M.K., Veldkamp L. Leadership, Coordination and Corporate Culture, 2014.

4 Nurlanova N. K. The problems of spatial modernization of the economy and new approaches to way

\section{СВЕДЕНИЯ ОБ АВТОРАХ}

Антон В. Богомолов к.э.н., преподаватель, кафедра экономики и бухгалтерского учета, Воронежский государственный промышленно-гуманитарный колледж, пр-т Революции, 20, г. Воронеж, 394036, Россия, иорioe@yandex.ru

Екатерина А. Белимова старший преподаватель, кафедра управления, организации производства и отраслевой экномики, Воронежский государственный университет инженерных технологий, пр-т Революции, 19, г. Воронеж, 394036, Россия, e.a.belimova@gmail.com

Елжан Б. Кушекбаев докторант, Алматинский университет управления, ул. Розыбакиева, 227, Алматы, 050060, Казахстан, yelzhan@gmail.com

\section{КРИТЕРИЙ АВТОРСТВА}

Все авторы в равной степени принимали участие в написании рукописи и несут ответственность за плагиат

\section{КОНФЛИКТ ИНТЕРЕСОВ}

Авторы заявляют об отсутствии конфликта интересов.

ПОСТУПИЛА 08.12.2016

ПРИНЯТА В ПЕЧАТЬ 01.02.2017 out from crisis: Kazakhstan"s experience. [Journal of Distribution Science]. 2013. pp. 39-48. (in Russian).

5 Fiordelisi F., Ricci O., Corporate culture and CEO turnover, J. Corp. Finance, 2013.

6 Querubin S.Y., Jon K.W. Developing corporate culture in a training department: a qualitative case study of internal and outsourced staff. Global Conference on Business and Finance. 2014. no. 1.

7 Varlamov N. V., Polyanin A. V. Scientific approaches for development of corporate management theory. [Russian journal of agricultural and socio-economic sciences]. 2017. vol. 62. no. 2. pp. 4-11. (in Russian).

\section{INFORMATION ABOUT AUTHORS}

Anton V. Bogomolov candidate of economical sciences, lecturer, economics and accounting department, Voronezh state industrial and humanitarian college, Revolution Av., 20 Voronezh, 394036, Russia, uopioe@yandex.ru

Ekaterina A. Belimova senior lecturer, management, production organization and industrial economy department, Voronezh state university of engineering technologies, Revolution Av., 19 Voronezh, 394036, Russia, e.a.belimova@gmail.com

Yelzhan B. Kushekbaev DBA student, Almaty management university, Rozybakiyev str, 227, Almaty, 050060, Kazakhstan, yelzhan@gmail.com

\section{CONTRIBUTION}

All the authors equally participated in writing the manuscript and are responsible for the plagiarism

\section{CONFLICT OF INTEREST}

The authors declare no conflict of interest.

RECEIVED 12.8.2016

ACCEPTED 2.1.2017 